\title{
Design on Online Examination System for College English
}

\author{
Sun $\mathrm{Na}$ \\ Bohai University, Jinzhou, P.R. China \\ sunna121013@126.com
}

Keywords: college English; online examination; development technology introduction; summary design; design of system process; database table design

\begin{abstract}
College English is a foreign language curriculum, strengthen the inspection information construction is the key to improve the students' English comprehensive ability. In order to quickly and easily test students' English learning situation for a period of time, realize English inspection information, designed on the online examination system of college English, lay the foundation for software development. The system mainly carries on development technology introduction, summary design, design of system process and database table design. Among them, summary design designs function of each module in detail; design of system process designs complete process of system procedure in detail; database table design designs associated table structure in database in detail. The research contents of this thesis have important significance to improve the quality of English learning and the students' English level etc.
\end{abstract}

\section{Introduction}

College English is a basic language courses, college English has two contents, one is the college English class for non-English major students, the other one is to lay a foundation for nature, to achieve the "College English Syllabus" four level requirements for the purpose of opening a basic English course [1]. The organization of traditional examination way generally have to go through the steps: manual, paper design, printing test paper, the examination room arrangement, examinee examination, examination paper collection, artificial volume change, performance reporting, results announced and exam evaluation etc. This will undoubtedly cause a great waste of manpower, material and financial resources and time, and work intensity, low efficiency, the students also feel bound and passive [2]. Errors may also be in the marking process, affect the test results. With the reform unceasingly thorough, the traditional examination way more and more can not meet the actual needs, and the online examination system based on campus network can break through the traditional way of examination to make examinations more flexible, but also can save a lot of time, manpower, material and financial resources, improve test efficiency and standard level [3,4]. In order to improve the English teaching quality and students' English level, realize English inspection information, designed on the online examination system of college English, lay the foundation for software development.

\section{Development Technology Introduction}

Based on the design of online examination system, this paper chooses the database for SQL server. Database design, interface design use the development language for ASP. NET. First of all, ASP. NET it is mainly used to create dynamic WEB applications. The compatibility is strong, it can not only be compatible with $\mathrm{C}$, C\#, can be compatible with many browsers, it ensures that the online examination system can run in many browsers, do not have to worry about compatibility issues, it also enhances the universality of the online examination system applications. ASP.NET sometimes also can be used as a programming language, associated with the ACTIVEX component, ASP command, HTML Webpage technologies to create an application based on WEB [5]. Secondly, ASP.NET is some code encapsulated in the control, through the JIT technology will translate the intermediate language into code, can be faster to invoke the WEB page, it also enhances the flexibility of the application of online examination system. 


\section{Summary Design}

Summary design is the next step to be analyzed, the main task is to get the DFD needs analysis converting software architecture [6]. Summary design usually use configuration diagram to depict a functional configuration of the software, the purpose is to ensure that based on the realization of logic model, as far as possible to improve the target system simplicity, variability, consistency, integrity, reliability, economy, efficiency and safety of operation. A structure diagram of the system shown in Fig. 1.

In Fig. 1, the name of the top level with a system of "college English online examination system" means. The second layer is divided into "students", "teachers" and "Administrator" three kinds of users, each represents a module. The third layer with specific functions of each module, where "students" user functions include online answer, extract papers, submit papers, query results; "teachers" user functions include mark papers, bank management, performance management, papers analysis; "administrator" user management functions, including teachers management, students management, system maintenance, system backup.

In each module, the definition of each specific function has its specific meaning. For example, in "students" module, online answer says students after a successful login according to random distribution questions in the question database to answer, in a specified time, complete answer, submit questions; in "teachers" module, bank management says teachers can add, modify and delete test information, randomly distribute questions of question bank to the online test students; in "administrator" module, system backup says administrator makes a backup of data of system-generated student achievement, to prevent data loss.

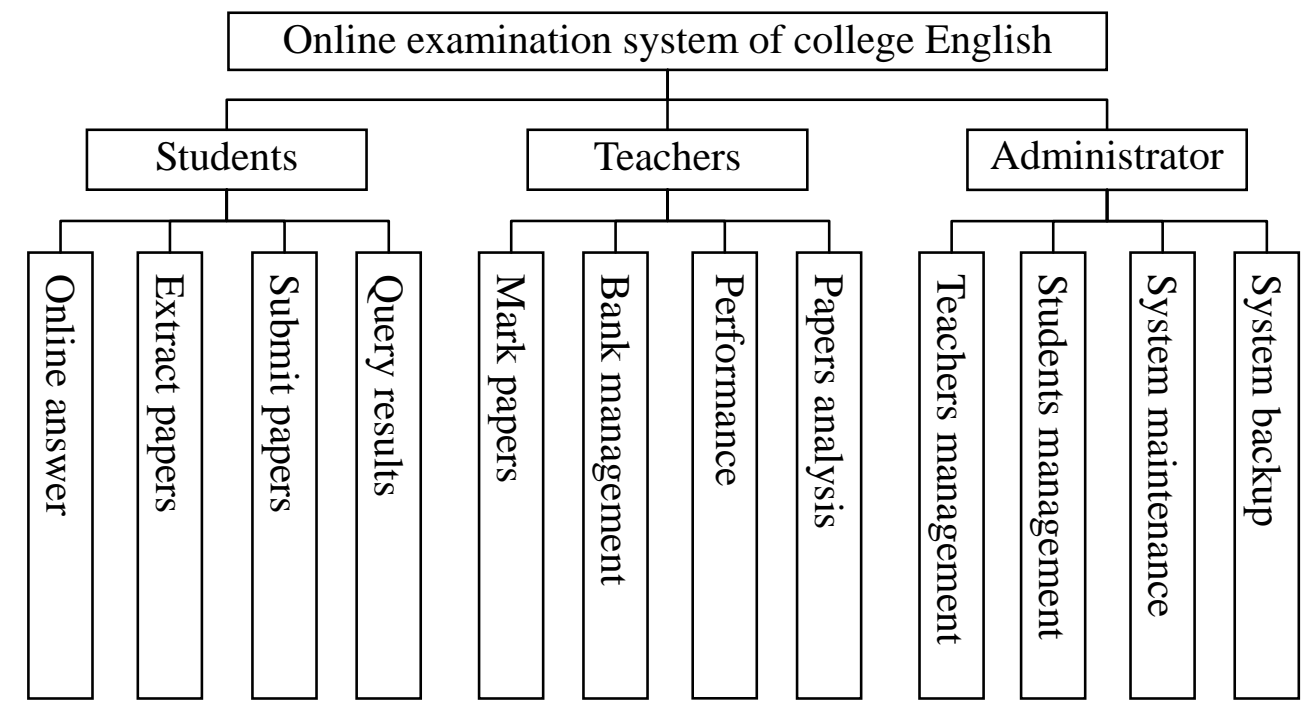

Fig. 1. Functional design of college English online examination system

\section{Design of System Process}

The system process can be depicted by flow chart of the system. The flow chart of the system is the traditional tools of drawing system physical model, expressing the flow of components of the system, rather than the control process of information processing [7]. The system is divided into students, teachers, administrators of three users, the user to students as an example to illustrate the process of the design of system process, as shown in Fig. 2.

System process design description: After the user starts the application, enter the login screen, when a user logs on to the system, the system prompts the user whether the account; if there is, the user is prompted to enter a user name and password; if not, the user is prompted to register account, after successful registration, re entering the login interface, input the registered user name and password. If the input is correct, enter the main interface, the user can select function, performs the required operation; otherwise, enter again, until you enter the correct user name and password, may 
also exit the system. When the user finishes execution of all operations, withdraw from the system, the end.

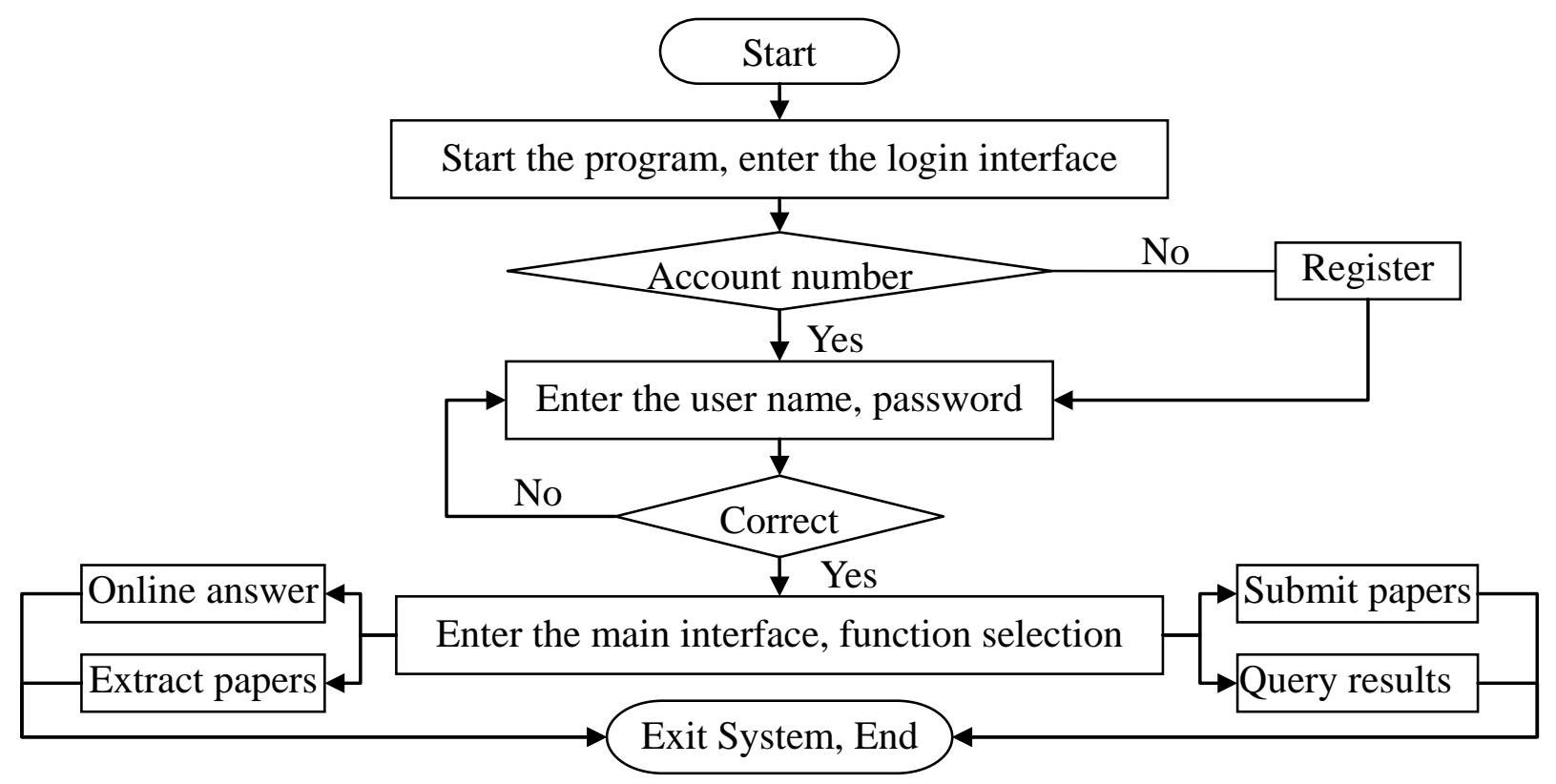

Fig. 2. Student user flow chart

\section{Database Table Design}

College English online examination system based on this paper, database includes user information table, performance information table and papers information table three categories. Among them, the user information table includes student information table, teacher information table and administrator information table; performance information table includes former student test scores table and the latest test scores table; papers information table includes the latest extracted papers information table and the previous exam papers information table.

Taking the design of student information table as an example, explains the structure of tables in the database. Student information table is used to record student information, specific table structure as shown in Table 1.

Table 1. Student information table

\begin{tabular}{c|c|c|c|c}
\hline Serial Number & Fields Name & Fields Type & Fields Width & Illustration \\
\hline 1 & Id & Varchar & 15 & Candidate number, primary key \\
\cline { 1 - 3 } 2 & Name & Varchar & 15 & Student name \\
\cline { 3 - 4 } 3 & Sex & Varchar & 10 & Student sex \\
\hline 4 & Number & Varchar & 15 & Student number \\
\hline 5 & Grade & Int & 4 & Student's grade \\
\hline 6 & Class & Int & 4 & Student's class \\
\hline 7 & Department & Varchar & 20 & Student's department \\
\hline 8 & Profession & Varchar & 20 & Student's profession \\
\hline
\end{tabular}

\section{Advantages and Disadvantages}

Advantages of online examination system is to use computer network platform to distribute test papers to students (terminal), at the end of the allotted time, the examinee's answer is transmitted to the system center. The entire process from the examination system center under unified 
management, without the participation of teachers, greatly reduces teachers questioning and correcting workload in the previous exam.

This is a new way of examination based on the information technology, not only break through the traditional forms of examination, prompting the exam results relatively objective; and the use of computer network platform to distribute the questions to the students, can distribute different test papers to adjacent examinees, more cases are in the question bank randomly selected questions for each examinee, the possibility of fraud will be reduced to the minimum, which is the traditional examination can not do.

The main disadvantage is to need perfect software and hardware conditions. This point along with the country to increase investment in education, the problem will gradually ease.

\section{Conclusion}

Information technology is a means and method for acquisition, storage, processing, transmission of information used by the system. Information technology is composed of three elements of information media, media application method and optimization method of information system [8]. At present, information technology has matured, wide application range, but is only used for public information services, campus network and other areas, rarely applied in the English examination. College English online examination system designed based on this paper, can fully use the information technology to master English learning situation of the students for a period of time, mobilize the enthusiasm of students learning English, has the important meaning for improving the quality of English teaching and the students' English level etc.

\section{Acknowledgement}

This work is supported by general subject of "the Twelfth Five-year Plan" on Educational Science of Liaoning Province, 2012, Approval (JG12DB213).

\section{References}

[1] J. G. Cai, "Motivation and trend analysis of the demise of College English," Foreign Languages Research, vol. 133, no. 3, pp. 46-52, 2012.

[2] Y. Yan, "Design and Exploration of Online English Examination System Based on ASP," Master’s degree of Jiangxi Science \& Technology Normal University, 2013.

[3] P. N. Xiao, X. T. Zhang, "Aiming at the drawbacks of traditional test model analysis and realization of online examination system based on Web," Digitization User, vol. 15, no. 6, pp. 49-50, 2013.

[4] J. Pei, "Design and Implementation of Higher Vocational Chinese Online Examination System Based on B/S," Master's degree of University of Electronic Science and Technology of China, 2011.

[5] Y. B. Li, "Key Technology Research Online Examination System," Software, vol. 35, no. 1, pp. 83-88, 2014.

[6] Baidu Encyclopedia, "Flow Chart," http://baike.baidu.com/view/1140574.htm?fr=aladdin, 2014-10-22.

[7] Baidu Encyclopedia, "Summary Design," http://baike.baidu.com/view/551728.htm?fr=aladdin, 2014-10-22.

[8] G. N. Nan, "How to Understand Information Technology and Formation of Teachers' IT Literacy," Modern Distance Education Research, vol. 121, no. 1, pp. 3-6, 2013. 